\title{
Statyba
}

\section{THERMAL TECHNICAL PROPERTIES OF ECOCOTTON}

\section{Gnip \& V. Keršulis}

To cite this article: I. Gnip \& V. Keršulis (1998) THERMAL TECHNICAL PROPERTIES OF ECOCOTTON, Statyba, 4:1, 43-48, DOI: 10.1080/13921525.1998.10531378

To link to this article: https://doi.org/10.1080/13921525.1998.10531378

册 Published online: 26 Jul 2012.

Submit your article to this journal $\pi$

III Article views: 67

4 Citing articles: 1 View citing articles 진 


\section{EKOVATOS ŠILUMINĖS TECHNINĖS SAVYBĖS}

\section{Gnip, V. Keršulis}

\section{Ivadas}

Lietuvos statybose plačiai naudojamos naujos efektyvios termoizoliacinès medžiagos. Reklaminio pobūdžio literatūroje gana dažnai peršama mintis apie jų universalumą. Pagrindiniu kriterijumi imamas sausų medžiagu šilumos laidumo koeficientas. Juo įvertinamas ekonominis šiltinimo efektyvumas, tačiau mažai atsižvelgiama ị kitas labai svarbias medžiagų charakteristikas - sorbcini drègni, šilumos imlumą, laidumą vandens garui, skaičiuojamaji šilumos laidumo koeficientą ir kt., nuo kuriụ priklauso apšiltintų atitvarų savybés eksploatacijos metu.

Viena iš tokių termoizoliaciniu medžiagu ekovata. Ją Lietuvoje 1993 metais pradejo gaminti tarptautinis SAF koncernas. Tai smulkiapluoštė vatos pavidalo medžiaga, susidedanti iš mechaniškai susmulkintos makulatūros su antipireno - boro rūgšties ir antiseptiko - borakso priedais.

Ekovatos taikymo rekomendacijos yra netikslios dèl patikimos informacijos trūkumo, nes jos šiluminès techninès savybès nebuvo giliau tyrinètos. Turimus duomenis sunku lyginti su informacija apie analogišką suomišką medžiagą Selluvilla-SV bei švedišką Cellulosic -1 [1].

Darbo tikslas - ištirti UAB "Ekovata" cechų pagamintos produkcijos šilumines technines savybes, jas palyginti su užsienyje gaminamụ analogiškụ medžiagu savybèmis, nustatyti jos skaičiuojamuosius šiluminius techninius rodiklius bei ivertinti efektyviausio naudojimo sritis.

\section{Tyrimu metodikos}

Ekovatos tankis (jos masès ir užimamo tūrio, iskaitant oro tarpus, santykis), drégnis ir borakso bei boro rūgšties kiekiai joje nustatyti pagal $[2,3]$. Ekovatos bandiniai buvo džiovinami $65^{\circ} \mathrm{C}$ temperatūroje, nes aukštesneje temperatūroje išsiskiria borakso kristalizacinis vanduo ir vyksta boro rūgšties destrukcija.
Ekovatos šilumos laidis esant $25^{\circ} \mathrm{C}$ temperatūrai nustatytas pagal [4], keičiant bandinių tankị nuo 35 iki $63 \mathrm{~kg} / \mathrm{m}^{3}$, o savitoji šilumine talpa rasta Vilniaus Gedimino technikos universiteto Fizikos katedroje pagal Maskvos fizikos-technikos instituto mažo tankio ir biriuju medžiagu šiluminès talpos nustatymo metodiką.

Ekovatos pusiausvirasis dregnis nustatytas pagal [5], $20^{\circ} \mathrm{C}$ temperatūroje palaipsniui keičiant santykini oro drègni nuo 40 iki $97 \%$. Kiekvienu atveju bandyta po 11 bandinių.

Laidis garui nustatytas pagal [6]. Bandinių kiekis -9 , ju aukštis $60 \mathrm{~mm}$, tankis $50 \mathrm{~kg} / \mathrm{m}^{3}$.

Bandymu rezultaty matematinis-statistinis apdorojimas atliktas pagal [7] su intervaliniu eksperimentiniu duomenu ìvertinimu, arba pagal [8] su atitinkamu empiriniu priklausomybiu sudarymu pasikliautinumo lygmeni abiem atvejais laikant lygiu $95 \%$

\section{Ekovatos sudẻtis ir šiluminès techninès savybès}

Ekovatos bandymų rezultatų matematinisstatistinis apdorojimas parode, kad Eigirgalos ir Pabrades cechu pagaminta produkcija pagal nustatytus rodiklius praktiškai nesiskiria.

Vidutinis ekovatos tankis yra $44 \pm 1 \mathrm{~kg} / \mathrm{m}^{3}$, boro rūgšties ir borakso kiekiai joje - atitinkamai $12 \pm 0,2 \%$ ir $8 \pm 0,3 \%$, o masès drègnis $-8,7 \pm 0,4 \%$. Nominalus Cellulosic-1 tankis yra $-35 \mathrm{~kg} / \mathrm{m}^{3}$, o masès drégnis $10 \%$ [1].

Ekovatos pusiausviriojo drègnio vidutinès reikšmès su suminiu neapibréžtumu pateiktos 1 lent. Palyginimui pateikti Suomijos valstybinio mokslinio tyrimo centro duomenys apie analogišką medžiagą Selluvilla-SV. Pateikti duomenys rodo, kad abieju medžiagu viso tirto santykinio oro diapazono pusiausvirasis drègnis praktiškai vienodas.

Ekovatos laidžio garui nustatymo statistinès analizès rezultatai pateikti 2 lent. Galima pažymèti, kad ekovatos laidžio garui reikšmé praktiškai yra tokia 
1 lentelè. Ekovatos ir Selluvilla-SV pusiausvirasis masès drègnis

Table 1. Equilibrium sorbative moisture content of Ecocotton and Selluvilla-SV

\begin{tabular}{|c|c|c|}
\hline \multirow{2}{*}{$\begin{array}{c}\text { Santykinis oro } \\
\text { drègnis, \% }\end{array}$} & \multicolumn{2}{|c|}{ Pusiausvirasis masès drègnis, \% } \\
\cline { 2 - 3 } & Ekovata & Selluvilla-SV \\
\hline 40 & $6,0 \pm 0,7$ & 6,8 \\
\hline 60 & $9,4 \pm 1,1$ & 9,4 \\
\hline 80 & $13,1 \pm 1,0$ & 13,2 \\
\hline 90 & $16,7 \pm 1,0$ & 17,0 \\
\hline 97 & $36,1 \pm 2,6$ & 35,3 \\
\hline
\end{tabular}

pat kaip $35-150 \mathrm{~kg} / \mathrm{m}^{3}$ tankio mineralinès vatos gaminių.

Sausos ekovatos bandinių savitoji šiluminè talpa esant $20-25^{\circ} \mathrm{C}$ temperatūrai sudaro $1040 \pm 100 \mathrm{~J} / \mathrm{kg} \cdot \mathrm{K}$.

Sausos ekovatos šilumos laidžio priklausomybe் nuo medžiagos tankio pateikta 1 pav. Šią priklausomybę galima išreikšti regresine lygtimi:

$$
\bar{\lambda}=0,042+0,000051 \cdot \rho_{0},
$$

čia $\bar{\lambda}$ - šilumos laidžio esant $25^{\circ} \mathrm{C}$ temperatūrai vidutinè reikšmè, $\mathrm{W} / \mathrm{m} \cdot \mathrm{K} ; \rho_{0}$ - sausu ekovatos bandiniy tankis, $\mathrm{kg} / \mathrm{m}^{3}$.

Šios lygties koreliacijos koeficientas 0,74, o vidutinis reliatyvusis kvadratinis nuokrypis 0,015 .

Ekovatos šilumos laidžio priklausomybę nuo drėgnio nustatėme, sausos medžiagos tankiui esant 61 $\pm 1,5 \mathrm{~kg} / \mathrm{m}^{3}$, o jos masès drégniui kintant nuo 6,1 iki $28,9 \%$ ( 2 pav.).

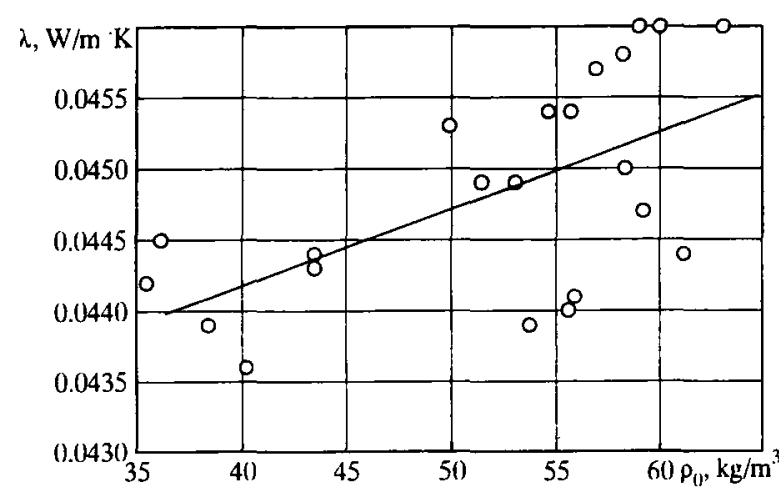

1 pav. Sausos ekovatos šilumos laidžio priklausomybè nuo tankio

Fig 1. The dependency of dry Ecocotton thermal conductivity on its density
2 lentelè. Ekovatos laidžio garui $(\mu)$ nustatymo rezultatai Table 2. Results of Ecocotton vapour permeability $(\mu)$ determination

\begin{tabular}{|l|c|}
\hline \multicolumn{1}{|c|}{$\begin{array}{c}\text { Laidis garui } \mu \text { ir jo statistiniai } \\
\text { parametrai }\end{array}$} & Vertès \\
\hline Nustatymu skaičius, vnt. & 9 \\
\hline $\begin{array}{l}\text { Aritmetinis } \mu \text { reikšmes vidurkis, } \\
\mathrm{mg} / \mathrm{m} \cdot \mathbf{h} \cdot \mathrm{Pa}\end{array}$ & 0,54 \\
\hline Empirinis standartas, $\mathrm{mg} / \mathrm{m} \cdot \mathbf{h} \cdot \mathrm{Pa}$ & 0,052 \\
\hline Variacijos koeficientas, $\%$ & 9,6 \\
\hline $\begin{array}{l}\text { Vidutinės } \mu \text { reikšmès galimas } \\
\text { minimalus dydis, } \mathrm{mg} / \mathrm{m} \cdot \mathbf{h} \cdot \mathrm{Pa}\end{array}$ & 0,50 \\
\hline $\begin{array}{l}\text { Vidutinès } \mu \text { reikšmès galimas } \\
\text { maksimalus dydis, } \mathrm{mg} / \mathrm{m} \cdot \mathbf{h} \cdot \mathrm{Pa}\end{array}$ & 0,58 \\
\hline
\end{tabular}

Matematiniais-statistiniais metodais apdorojus šių tyrimų rezultatus (2 pav.), gauta tokia ekovatos šilumos laidžio priklausomybès nuo drègnio regresinè lygtis su koreliacijos koeficientu 0,91 ir vidutiniu reliatyviuoju kvadratiniu nuokrypiu 0,06:

$$
\bar{\lambda}_{w}=0,045+0,0014 \cdot W_{s},
$$

čia $W_{s}$ - ekovatos masès drègnis, $\%$.

Formulès (2) koeficientas prie $W_{s}$ nurodo šilumos laidžio prieaugị, kai medžiagos masès drègnis padidèja $1 \%$.

Bandymų rezultatai ( 2 pav., 2 formulè) rodo, kad tarp ekovatos šilumos laidžio ir drégnio yra linijinè priklausomybe், ir vidutinis šilumos laidžio prieaugis, padidèjus masès drégniui $1 \%$, nepriklauso nuo jau esančios medžiagos drègmès (atliktụ bandymų).

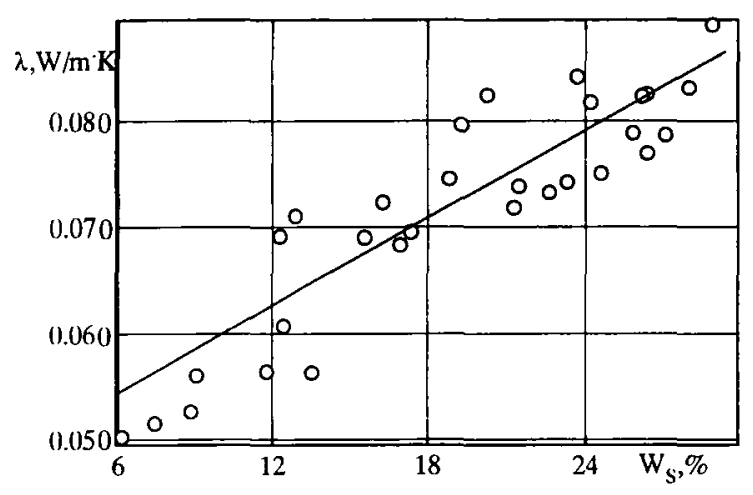

2 pav. Sausos $61 \pm 1,5 \mathrm{~kg} / \mathrm{m}^{3}$ tankio ekovatos šilumos laidžio priklausomybè nuo jos drègnio

Fig 2. The dependency of dry $61 \pm 1,5 \mathrm{~kg} / \mathrm{m}^{3}$ density Ecocotton thermal conductivity on its moisture content (wt.\%) 


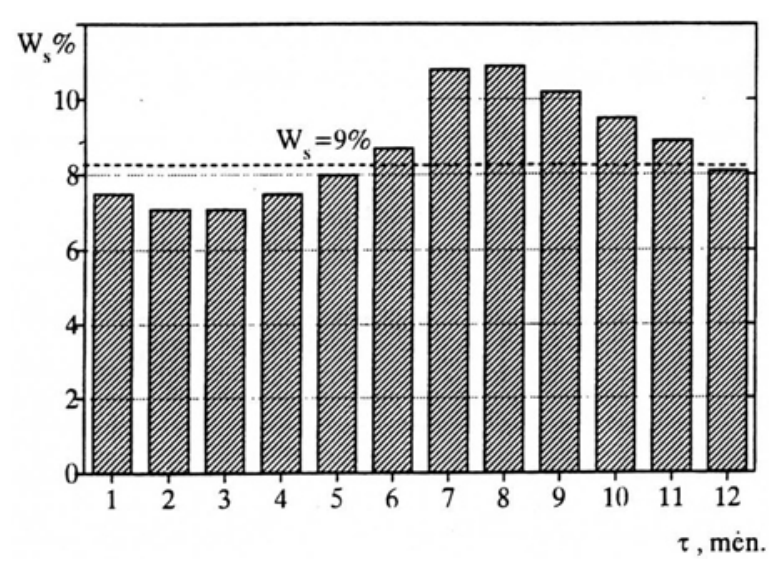

3 pav. Viso ekovatos Selluvilla-SV palepès perdenginio sluoksnio drégnio vidutiniu reikšmiu pasiskirstymas pagal mènesius

Fig 3. The monthly distribution of average moisture content in all layers of Ecocotton Selluvilla-SV used for insulating attic floor (Finland data)

\section{Skaičiuojamieji ekovatos šiluminiai techniniai rodikliai}

Skaičiuojamasis ekovatos šilumos laidis rastas įvertinus jos pusiausviraji dregni atitvaroje eksploatacijos sallygomis.

Mũsų atlikti natūriniai tyrimai (3 lent.) rodo, kad vidutinis viso ekovatos sluoksnio masès drègnis palèpès perdangos konstrukcijoje po vienerių metų eks- ploatacijos sudaro 8 - 9\%. Atlikę SLV-2 tipo atitvaru [9] su vedinamu oro tarpu ir šiltinančiu ekovatos sluoksniu drègminio režimo skaičiavimus gavome tokią pat ekovatos masès drègnio reikšmę šalčiausiam metụ mènesiui.

4 lent. ir 3 pav. pateikti mūsų surinkti ir apibendrinti duomenys apie analogiškos ekovatai suomiškos medžiagos Selluvilla-SV, naudotos palèpès šiltinimui, drègnio tyrimus Suomijos valstybiniame mokslinio tyrimo centre. Temperatūra tiriamo pastato viduje buvo $+20^{\circ} \mathrm{C}$, o vidutine lauko oro temperatūra žiemą - nuo -5 iki $-6{ }^{\circ} \mathrm{C}$, rudeni ir pavasari - nuo $-1,0$ iki $1,5^{\circ} \mathrm{C}$ ir vasarą - nuo $+12 \mathrm{iki}+15^{\circ} \mathrm{C}$.

Iš 4 lent. matome, kad žiemos mènesiais drégmès kiekis šios ekovatos apatiniuose sluoksniuose neviršija $5-6 \%$ ir tik pačiame viršutiniame sluoksnyje siekia 17$18 \%$ ribą.

Vidutinis viso Selluvilla-SV sluoksnio masès drègnis ( 3 pav.) per 8 metų mènesius neviršija $9 \%$ ir tik vasaros $(7,8)$ bei rudens $(9,10)$ menesiais yra didesnis - pasiekia 10,9\% ribą. Drégnio didejjimas pastebimas, kai patalpos nešildomos.

Vidutinis šios ekovatos sluoksnio masès drègnis per visus metus sudaro $8,7 \%$. Tarus, kad pusiausvirasis dregnis lygus $9 \%$, drègnio histogramos dalis su didesnemis reikšmèmis sudaro tik $5,5 \%$ dalies su mažesnèmis negu $9 \%$ reikšmèmis.

3 lentelè. Ekovatos, naudotos palèpių izoliavimui, drègnio pasiskirstymas pagal sluoksnio storị

Table 3. The layer distribution of moisture content in Ecocotton used for insulating attic floor

\begin{tabular}{|c|c|c|c|c|c|}
\hline \multirow{2}{*}{ Objektas } & \multirow[t]{2}{*}{$\begin{array}{c}\text { Objekto aprašymas ir bandinių } \\
\text { paemimo vieta* }\end{array}$} & \multirow{2}{*}{$\begin{array}{l}\text { Ekovatos } \\
\text { užpylimo laikas } \\
\text { ir } \\
\text { eksploatavimo } \\
\text { sąlygos }\end{array}$} & \multirow{2}{*}{$\begin{array}{c}\text { Sluoksnis, kuriame } \\
\text { nustatytas drègnis } \\
\text { (iš apačios i viršu), } \\
\text { mm }\end{array}$} & \multicolumn{2}{|c|}{$\begin{array}{l}\text { Ekovatos masés } \\
\text { drégnis } \mathrm{W}_{\mathrm{s}}, \%\end{array}$} \\
\hline & & & & $\begin{array}{l}\text { kiekvieno } \\
\text { sluoksnio }\end{array}$ & $\begin{array}{l}\text { vidutiniš- } \\
\text { kai }\end{array}$ \\
\hline $\begin{array}{l}\text { UAB } \\
\text { "Lietžaliava" } \\
\text { I korpusas } \\
\text { Vytenio g.9, } \\
\text { Vilnius }\end{array}$ & $\begin{array}{l}\text { Konstrukcija (iš apačios ị viršu): } 10 \text { - } \\
12 \mathrm{~cm} \text { pločio lentos su } 12 \mathrm{~cm} \text { tarpais; } \\
\text { garu izoliacija - } 160 \mu \mathrm{m} \text { storio polieti- } \\
\text { leno plèvele; ekovatos sluoksnis - } 16 \\
\mathrm{~cm} \text {. Bandiniai imti perdangos centre }\end{array}$ & $\begin{array}{l}1995 \text { m. spalis } \\
\text { Pastatas } \\
\text { šildomas }\end{array}$ & $\begin{array}{r}80 \\
140 \\
\end{array}$ & $\begin{array}{l}8.3 \\
7.4 \\
\end{array}$ & 7.9 \\
\hline $\begin{array}{l}\text { Privatizuotas ir } \\
\text { pertvarkytas i } \\
\text { gyvenamajị } \\
\text { Verkių dvaro } \\
\text { techninis } \\
\text { pastatas, } \\
\text { Žaliujụ ežerụ } \\
\text { g. } 3 \text {, Vilnius }\end{array}$ & $\begin{array}{l}\text { Konstrukcija (iš apačios i viršu): } \\
\text { lentos; oro tarpas; lentos; } 05-2 \mathrm{~cm} \\
\text { molio sluoksnis; ekovatos sluoksnis - } \\
14,5 \mathrm{~cm} \text {; lentos su } 0,5-1 \mathrm{~cm} \text { tarpais. } \\
\text { Viršutinis ekovatos paviršius su } \\
\text { plutele (po užpylimo buvo drekintas } \\
\text { vandeniu). Bandiniai imti } 25 \mathrm{~cm} \\
\text { atstumu nuo mūrinès lauko sienos }\end{array}$ & $\begin{array}{l}1995 \mathrm{~m} \text {. } \\
\text { rugsejjis } \\
\text { Pastatas } \\
\text { šildomas }\end{array}$ & 120 & 9.7 & 9.1 \\
\hline
\end{tabular}

* Ekovatos bandiniai iš atitvarų paimti 19960826. 
4 lentelè. Ekovatos Selluvilla-SV, naudotos palèpès izoliavimui ", drègnio pasiskirstymas pagal sluoksnio storị ir metų laiką

Table 4. The layeral and monthly distribution of moisture in Ecocotton Selluvilla-SV used for insulating of attic floor (Finland data)

\begin{tabular}{|c|c|c|c|c|c|c|c|c|c|c|c|c|}
\hline \multirow{2}{*}{$\begin{array}{c}\text { Sluoksnis, kuriame } \\
\text { nustatytas drègnis } \\
\text { (iš apačios i viršu), } \\
\text { mm }\end{array}$} & \multicolumn{12}{|c|}{ Ekovatos masès drégnio pasiskirstymas pagal mènesius, \% } \\
\hline & 1 & 2 & 3 & 4 & 5 & 6 & 7 & 8 & 9 & 10 & 11 & 12 \\
\hline 50 & 5.1 & 5.0 & 5.2 & 6.0 & 7.0 & 8.0 & 10.0 & 9.6 & 8.0 & 7.0 & 6.0 & 5.5 \\
\hline 100 & 5.6 & 5.5 & 5.7 & 6.0 & 7.0 & 8.0 & 10.3 & 10.0 & 9.0 & 7.5 & 6.5 & 6.0 \\
\hline 150 & 6.0 & 6.0 & 6.3 & 7.0 & 8.0 & 8.5 & 10.7 & 10.8 & 10.0 & 8.5 & 7.5 & 7.0 \\
\hline 200 & 7.0 & 7.0 & 7.4 & 8.0 & 8.5 & 9.0 & 11.0 & 11.5 & 11.0 & 10.0 & 10.0 & 8.0 \\
\hline 250 & 10.0 & 9.0 & 9.0 & 9.1 & 9.4 & 9.0 & 11.5 & 12.0 & 12.3 & 12.0 & 11.5 & 10.5 \\
\hline 300 & 17.0 & 15.0 & 13.0 & 12.0 & 11.0 & 11.0 & 12.0 & 13.0 & 14.0 & 16.5 & 18.0 & 17.0 \\
\hline
\end{tabular}

* Perdangos konstrukcija (iš apačios ị viršų): medžio drožliụ plokšte - $12 \mathrm{~mm}$, garo izoliacinè plèvelè, ekovatos sluoksnis $300 \mathrm{~mm}$.

5 lentelè. Ekovatos šiluminiai techniniai rodikliai

Table 5. Thermal technical values of Ecocotton

\begin{tabular}{|c|c|c|c|c|c|c|c|}
\hline \multirow[b]{2}{*}{$\begin{array}{l}\text { Termoizoliacine } \\
\text { medžiaga }\end{array}$} & \multicolumn{4}{|c|}{ Eksperimentinès sausos medžiagos charakteristikos } & \multicolumn{3}{|c|}{ Skaičiuojamieji rodikliai } \\
\hline & $\begin{array}{c}\text { Tankis } \\
\rho_{0}, \\
\mathrm{~kg} / \mathrm{m}^{3}\end{array}$ & $\begin{array}{l}\text { Šilumine } \\
\text { talpa } \mathrm{C}_{0} \\
\mathrm{~kJ} / \mathrm{kg} \cdot \mathrm{K} .\end{array}$ & $\begin{array}{c}\text { Šilumos } \\
\text { laidis } \lambda_{0}, \\
\mathrm{~W} / \mathrm{m} \cdot \mathrm{K}\end{array}$ & $\begin{array}{c}\text { Gary laidis } \\
\mu, \\
\mathrm{mg} / \mathrm{m} \cdot \mathrm{h} \cdot \mathrm{Pa}\end{array}$ & $\begin{array}{c}\text { Svorinis } \\
\text { drégnis } \mathrm{W}_{\mathrm{s}} \text {, } \\
\%\end{array}$ & $\begin{array}{l}\text { Šilumos } \\
\text { laidis } \lambda, \\
\mathrm{W} / \mathrm{m} \cdot \mathrm{K}\end{array}$ & $\begin{array}{c}\text { Šilumos } \\
\text { imlumo } \\
\text { (24 h periodui) } \\
\text { koeficientas } S, \\
\mathrm{~W} / \mathrm{m}^{2} \cdot \mathrm{K}\end{array}$ \\
\hline Ekovata & 35 & 1.04 & 0.044 & 0.58 & 9 & 0.057 & 0.45 \\
\hline & 50 & 1.04 & 0.045 & 0.58 & 9 & 0.058 & 0.55 \\
\hline $\begin{array}{c}\text { (TS 5967247- } \\
01-93 \text { ) }\end{array}$ & 75 & 1.04 & 0.046 & 0.58 & 9 & 0.059 & 0.68 \\
\hline
\end{tabular}

Atlikti tyrimai ir jų rezultatų (3, 4 lent. 3 pav.) analizè rodo, kad šiluminiams techniniams skaičiavimams pusiausviraji ekovatos drégni galima laikyti lygiu 9\%. Tada ekovatos šilumos laidžio prieaugis $\Delta \lambda_{W_{s}}$ dèl jos įdrékimo pagal 2 lygti sudarys

$$
\Delta \lambda_{W s}=0,0014 \cdot W_{s}=0,0014 \cdot 9 \approx 0,013 \mathrm{~W} / \mathrm{m} \cdot \mathrm{K},
$$

o skaičiuojamasis šilumos laidis $35 ; 50$ bei $75 \mathrm{~kg} / \mathrm{m}^{3}$ tankio ekovatos atvejais bus lygus atitinkamai 0,057 ; 0,058 ir $0,059 \mathrm{~W} / \mathrm{m} \cdot \mathrm{K}$.

Ekovatos šilumos imlumo koeficientas $S_{z}$ $\left(\mathrm{W} / \mathrm{m}^{2} \cdot \mathrm{K}\right)$ temperatūros svyravimų periodui $z=24 \mathrm{~h}$ skaičiuotas pagal formulę [10]:

$$
S_{z=24}=0.27 \sqrt{\rho_{w} \cdot C_{w} \cdot \lambda},
$$

čia $\rho_{w}$ - drègnos ekovatos tankis, $\mathrm{kg} / \mathrm{m}^{3}$, apskaičiuotas pagal formulę $\rho_{w}=\rho_{0}\left(1+0,01 W_{s}\right) ; C_{w}$ drégnos ekovatos savitoji šiluma, $\mathrm{kJ} / \mathrm{kg} \cdot \mathrm{K}$, apskaičiuota pagal formulę

$$
C_{w}=\frac{C_{0}+0.01 \cdot W_{s} \cdot C_{v}}{1+0.01 \cdot W_{s}},
$$

čia $C_{0}$ - sausos ekovatos savitoji šiluma, $\mathrm{kJ} / \mathrm{kg} \cdot \mathrm{K} ; C_{v}$. vandens savitoji šiluma, $\mathrm{kJ} / \mathrm{kg} \cdot \mathrm{K}$.

35 ; 50 ir $75 \mathrm{~kg} / \mathrm{m}^{3}$ tankio ekovatos skaičiuojamasis šilumos imlumo koeficientas $24 \mathrm{~h}$ periodui sudaro atitinkamai $0.45 ; 0.55$ ir $0.68 \mathrm{~W} / \mathrm{m}^{2} \cdot \mathrm{K}$.

Eksperimentiniai ir skaičiuojamieji ekovatos šiluminiai techniniai rodikliai patekti 5 lentelejje.

Sausos $35 \mathrm{~kg} / \mathrm{m}^{3}$ tankio Cellulosic-1 šilumos laidis $10^{\circ} \mathrm{C}$ temperatūroje sudaro 0,037 , o skaičiuojamasis $0,045 \mathrm{~W} / \mathrm{m} \cdot \mathrm{K}$ [1]. Skirtumą tarp ivvairių sausų medžiagų šilumos laidumo reikšmiu galima paaiškinti skirtingomis tankio nustatymo metodikomis: ekovata apspaudžiama $100 \mathrm{~Pa}$ apkrova [2], o Cellulosic-1, kaip priimta EN ir ISO standartuose - $50 \mathrm{~Pa}$ apkrova. Šiam skirtumui turi itakos ir skirtingos šilumos laidumo matavimo temperatūros (10 ir $25^{\circ} \mathrm{C}$ ). Skirtumus tarp skaičiuojamưjụ šilumos laidžio reikšmių taipogi lemia skirtingos skaičiavimo metodikos. Pavyzdžiui, Suomi- 
joje $35 \mathrm{~kg} / \mathrm{m}^{3}$ tankio Selluvillai-SV šis rodiklis, apskaičiuotas $10^{\circ} \mathrm{C}$ temperatūrai, nèra pastovus, bet atsižvelgiant $i$ atitvaros apsaugą nuo garu ir vejo tipo, svyruoja nuo $0,041 \mathrm{iki} 0,050 \mathrm{~W} / \mathrm{m} \cdot \mathrm{K}$ [11]. Pas mus galiojančiose statybos normose [12] i tai kol kas neatsižvelgiama, todél skaičiuojamieji rodikliai yra pastovūs.

Atlikti tyrimai ir skaičiavimai rodo (3, 4 lent., 3 pav.), kad efektyviausia ekovatos panaudojimo sritis vedinamy atitvary (palepių, vertikaliuju ir šlaito išorinių sienų su ventiliuojamu oro tarpu) šiltinimas. Nešildymo periodu ( 7 - 10 mèn.) įdrékęs ekovatos šiltinantis sluoksnis šildymo periodo pradžioje (11-12 mèn.) greitai išdžiūsta ir ekovatos termoizoliacinès savybès šiuo periodu (12-5 mèn.) yra geriausios.

Nevédinamose atitvarose, jei vidinès sienos dalies varža garams yra nepakankama [13] ir dar atitvaroje yra daug šalčio tiltelių, besikaupianti šiltinančio sluoksnio drègmé gali nespèti pasišalinti per išorinę sienos dali ir net kondensuotis šiame sluoksnyje. Tokios atitvaros ekovatos drégnis, sprendžiant pagal sorbcijos izotermą ( 1 lent.) ir 4 lent. duomenis, gali pasiekti $12 \%$ ir daugiau. Todel projektuojant nevedinamas atitvaras su ekovatos šiltinančiu sluoksniu kiekvienu konkrečiu atveju turi büti teisingai parenkama jụ varža garams.

\section{Išvados}

1.Termoizoliacinès medžiagos ekovatos šilumos laidis labiau priklauso nuo drègnio negu nuo tankio. Tai patvirtina pateiktos šių priklausomybiu regresinès lygtys (1) ir (2).

2. Nustatyta, kad pusiausvyrinis ekovatos dregnis, lemiantis jos izoliacines savybes, vedinamose atitvarose sudaro ne daugiau $9 \%$. Nevedinam 4 arba blogai suprojektuotụ atitvarų ekovatos drégnis gali siekti $12 \%$ ir daugiau. Todel efektyviausia ekovatos naudojimo sritis - vedinamos atitvaros. Kitais naudojimo atvejais būtina parinkti atitvaros varžą garams taip, kad ekovatos vidutinis drégnis neviršytụ $9 \%$.

3. Rasti ekovatos skaičiuojamieji šiluminiai techniniai rodikliai, kurie gali būti panaudoti projektuojant sienų ir palépių šiltinimą. Pasiūlyta juos įtraukti ị rengiamas naujas Lietuvos Respublikos statybos normas "Pastatų atitvarų šiluminè technika".

\section{Literatūra}

1. B. Svennerstedt. Field Data on Settling in Loose - Fill Thermal Insulation // Insulation Materials, Testing, and
Applications, ASTM STP 1030, D.L. Mc Elroy and J.F. Kimpflen, Eds., American Society for Testing and Materials, Philadelphia, 1990, p. 231 - 236.

2. TS 5967247-01-93. Izoliacinè medžiaga Ekovata. Techninès sąlygos.

3. ГОСТ 17177-87. Материалы и изделия строительные теплоизоляционные. Методы контроля.

4. ГОСТ 7076-87. Материалы и изделия строительные. Метод определения теплопроводности

5. ГОСТ 24816-81. Материалы строительные. Метод определения сорбционной влажности.

6. ГОСТ 25898-83. Материалы и изделия строительные. Методы определения сопротивления паропроницанию.

7. Л.3. Румшиский. Математическая обработка результатов эксперимента: Справочное руководство. М: Наука, 1971. 192 с.

8. С.А. Айвазян. Статистическое исследование зависимостей. Применение методов коррелящионного и регрессионного анализов и обработка результатов эксперимента. M: Металтургия, 1968. $228 \mathrm{c}$.

9. Rekomenduojami gyvenamuju namų apšiltinimo techniniai sprendimai: Katalogas. Šiauliai: UAB "Pastatų konstrukcija", 1995.

10. Р.В. Щекин. Теплотехнические расчеты ограждающих конструкщий отапливаемых зданий. Киев: Будивэльник, 1966. 113 с.

11. Suomijos aplinkos apsaugos ministerijos leidimas celiuliozes vatai (ekovatai) SV Nr. 87/5331, 19920529. Vert. iš suomių kalbos.

12. RSN 143-92. Pastatų atitvarụ šiluminé technika. Vilnius, 1992. $71 \mathrm{p}$

13 В.М. Ильинский. Строительнная теплофизика. М.: Высшая школа, 1974. 317 с.

İteikta 19970702

\section{THERMAL TECHNICAL PROPERTIES OF ECOCOTTON}

\section{Gnip, V. Keršulis}

Sum mary

The purpose of this investigation was to determine thermal technical properties of Ecocotton (or Ecofibre) thermoinsulating material produced from waste newspaper, boric acid and borax and to evaluate the most optimal areas for application of this material on the basis of this investigation.

The density, antiseptic and antipirene quantities of the samples were determined according to [2], thermal conductivity at $25^{\circ} \mathrm{C}-$ [4], equilibrium sorbative moisture content - [5], vapour permeability - [6].

The dependencies of dry Ecocotton thermal conductivity on its density and moisture content are given in Figs 1 and 2 as well as after mathematical statistical treatment using the regressive equations (1) and (2). These dependencies are linear. Ecocotton specific heat at $20-25^{\circ} \mathrm{C}$ is $1040 \pm 100 \mathrm{~J} / \mathrm{kg} \cdot \mathrm{K}$. 
The determined equilibrium sorbative moisture content dependency on air relative humidity is given in Table 1 together with literature data about analogous Finnish material Selluvilla-SV. The difference between our and literature data is not significant.

The vapour permeability results for Ecocotton are given in Table 2 . This value is close to that for mineral wool products.

The data about layeral and seasonal distribution of moisture content in Ecocotton and analogous Finnish product Selluvilla-SV used for insulating of attic floors are given in Tables 3, 4 and Fig 3 . It was proved on the basis of these results and equilibrium moisture content calculations of building enclosures with insulating layer of Ecocotton, that the calculated equilibrium moisture content of Ecocotton is $9 \%$ (to mass). The calculated thermal conductivity and heat capacity coefficients of Ecocotton were calculated according to formulas (3) and (4).

Experimental (specific heat $\mathrm{C}_{\mathrm{l}}, \mathrm{kJ} / \mathrm{kg} \cdot \mathrm{K}$ : thermal conductivity $\lambda_{0}, \mathrm{~W} / \mathrm{m} \cdot \mathrm{K}$ ) and calculated (weight moisture content $\mathrm{W}_{\mathrm{s}} \%$; thermal conductivity $\lambda, \mathrm{W} / \mathrm{m} \cdot \mathrm{K}$; heat capacity coefficient $\mathrm{S}, \mathrm{W} / \mathrm{m}^{2} \mathrm{~K}$; vapour permeability $\mu, \mathrm{mg} / \mathrm{m} \cdot \mathrm{h} \cdot \mathrm{Pa}$ ) thermal technical values for 35,50 and $75 \mathrm{~kg} / \mathrm{m}^{3}$ density Ecocotton are given in Table 5.

The most optimal areas for application of Ecocotton are insulation of building enclosures with ventilated air space.
Ivan GNIP. Doctor (technical sciences). Head of Building Materials Employment Laboratory. Institute Termoizoliacija, Linkmenu 28, 2600 Vilnius, Lithuania.

A graduate of Kaunas Polytechnic Institute (Civil engineer faculty),1963. Doctor, 1992 (thermal insulation materials and products). Author of 58 papers, 6 inventions. Research interests: building thermal insulation materials and products, heat engineering aspects of their employment.

Vladislovas KERŠULIS. Doctor (natural sciences). Senior Researcher. Institute Termoizoliacija (Building Materials Employment Laboratory). Linkmenų 28, 2600 Vilnius, Lithuania.

A graduate of Moscow Chemical Technology Institute (Engineering physical-chemical faculty), 1967 (industrial engineer). Doctor, 1970 (radiation chemistry problems). Author of 67 papers, 8 inventions. Research interests: thermal insulation materials, their properties, technology and ecological aspects. 